\title{
Osteopontin is involved in TLR4 pathway contributing to ovarian cancer cell proliferation and metastasis
}

\author{
Cong Xu1 ${ }^{1,2, *}$, Hua Li ${ }^{1, *}$, Miao Yin ${ }^{1}$, Tao Yang ${ }^{1}$, Liguo An ${ }^{1}$ and Guiwen Yang ${ }^{1}$ \\ ${ }^{1}$ Shandong Provincial Key Laboratory of Animal Resistance Biology, College of Life Sciences, Shandong Normal University, \\ Jinan 250014, China \\ ${ }^{2}$ College of Pharmacy, Binzhou Medical University, Yantai 264003, China \\ *These authors contributed equally to this work
}

Correspondence to: Guiwen Yang, email: yanggw@sdnu.edu.cn

Liguo An, email: an.liguo58@gmail.com

Keywords: osteopontin, TLR4, proliferation, metastasis, ovarian cancer

Received: July 02, 2017 Accepted: September 23, $2017 \quad$ Published: October 12, 2017

Copyright: $\mathrm{Xu}$ et al. This is an open-access article distributed under the terms of the Creative Commons Attribution License 3.0 (CC BY 3.0), which permits unrestricted use, distribution, and reproduction in any medium, provided the original author and source are credited.

\section{ABSTRACT}

Tumor cell proliferation and metastasis are critical for tumor progression and lead to death of cancer patients. TLR4 is a member of the toll-like receptor (TLR) family, which promotes tumor growth, metastasis and immune escape. Osteopontin (OPN), a phosphorylated glycoprotein extensively expressed in multiple cell-types, plays important roles in tumorigenesis, metastasis and infiltration, and participates in signal transduction of innate immunity. However, it is unclear whether TLR4 has any relationship with OPN. The current study investigated the role of TLR4 and OPN in tumor proliferation and metastasis, and the potential effect of TLR4 signaling on OPN using the human ovarian cancer cell line HO-8910PM. High expression levels of TLR4 and OPN were detected in HO-8910PM cells, which promoted the proliferation, migration and invasion of tumor cells. Lipopolysaccharide (LPS) induced activation of TLR4 up-regulated OPN, increasing the malignant phenotype of cells. RNAi-mediated knockdown of OPN reduced significantly the metastatic phenotype activated by TLR4. Taken together, our study demonstrates that OPN contributes to the ovarian cancer cell proliferation and metastasis, which is activated by TLR4 signaling pathway. It provides new insights for the mechanisms of tumor development and metastasis, and suggests targeting TLR4 and OPN as an intervention in the ovarian cancer treatment.

\section{INTRODUCTION}

Toll-like receptors (TLRs) are well conserved pattern-recognition receptors (PRRs) that are primarily expressed in human immune cells and epithelial cells. These receptors play important roles in innate immune and adaptive immune responses through recognition of pathogen-associated molecular patterns (PAMPs) $[1,2]$. Recent studies have reported that TLRs are also expressed in many tumor cells, and play key functions in tumorigenesis, development, and metastasis [3, 4]. Tolllike receptor 4 (TLR4) is a member of the TLR family which is well-known for recognizing lipopolysaccharide (LPS), a component in many Gram-negative bacteria and selective Gram-positive bacteria [5]. TLR4 was reported to promote tumor growth, metastasis, and immune escape in many tumor cells [6, 7]. Haricharan et al. demonstrated that TLR4 activated secretion of pro-growth cytokines that promoted the growth of TP53 mutant breast cancer cells [8]. Kim et al. found that in epithelial ovarian carcinoma cells expressing TLR4 and MyD88, pro-inflammatory cytokines were constitutively secreted and directly contributed to cancer cell survival and progression [9]. He et al. used LPS to activate the TLR4 signal in lung cancer cells, which induced the expression of immune suppression factors, such as TGF- $\beta$, VEGF, IL-8, and assisted the immune escape of cancer cells [10].

Osteopontin (OPN) is a phosphorylated glycoprotein that is ubiquitously expressed in multiple tissues and cell-types. It has been shown to have multiple functions, such as regulation of macrophage homing, activation of $\mathrm{T}$ cells, neovascularization, inhibition of apoptosis, and 
reconstruction of extracellular matrix $[11,12]$. OPN also plays important roles in the formation, metastasis and invasion of malignant tumor cells [13, 14]. Several studies have proven that increased OPN expression is associated with advanced tumor stage, poor prognosis and tumor metastasis $[15,16]$. Overexpression of OPN increased cell proliferation, migration, invasion and tumor formation in human ovarian, prostate, lung and liver cancer cells [17-19]. In addition, high levels of OPN expression were observed in multiple tumor tissues and blood samples of patients with malignant tumors, indicating that OPN overexpression contributed to cancer development and metastasis [20, 21].

Moreover, Zhao et al. demonstrated that the intracellular OPN expression could be increased by activating TLR4 in mouse macrophages [22]. These results suggest a possible relationship between TLR4 and OPN in immune cells. As OPN is involved in innate immunity signal transduction $[23,24]$, it is likely to be involved in signals mediated by TLR4. Therefore, we seek to investigate whether TLR4 and OPN work together to mediate tumor cell invasion and metastasis.

Ovarian cancer is one of the common cancers in female reproductive organs. It ranks eighth in the incidence of all cancers among women worldwide, and is the leading cause of cancer-related death from gynecological cancers in China [25]. In the current study, the human ovarian cancer cell line, HO-8910PM, was investigated to examine the expression levels of TLR4 and OPN in ovarian cancer cells. We used TLR4 specific agonist and inhibitor, and shRNA-mediated knockdown of OPN to explore the effect and mechanism of TLR4 signaling on OPN expression and the metastatic phenotype of cancer cells. Taken together, our study investigates the mechanisms of tumorigenesis, development, and metastasis, and provides evidence for the combined targeting of TLR4 and OPN in the treatment of ovarian cancer.

\section{RESULTS}

\section{Expression of TLR4 and OPN in ovarian cancer cells}

The mRNA expression levels of TLR3-TLR9 were measured in HO-8910PM cells, and quantified using Band Scan5.0 software to analyze the optical density ratio between the TLR gene amplicon and the internal reference amplicon. TLR1 and TLR2 were not detected in the cells, while high levels of TLR3 and TLR4 were detected (Figure 1A-1B).

Three kinds of splicing isoforms are present in OPN: OPN-a (full-length form), OPN-b (lacking exon 5), and OPN-c (lacking exon 4) [26]. Specific primers were designed according to the differences in the mRNA structures of the three isoforms, and the basal expression levels in the tumor cells were tested through RT-PCR using
HO-8910PM cell cDNA as the template. The mRNAs of OPN-a, OPN-b, and OPN-c exhibited different expression levels in HO-8910PM cells; while the expression level of OPN-a was similar to that of OPN-b, OPN-c was lower than OPN-a and OPN-b (Figure 1C-1D). The OPN protein levels in cellular supernatant were further tested via immunoblotting (IB), and the results were consistent with RT-PCR (Figure 1E).

The human OPN polyclonal antibody used in IB can identify the C-terminal segment of OPN created by the digestion of thrombin or matrix metalloproteinase. Our results revealed that the OPN segment with a molecular weight of $32 \mathrm{kDa}(\mathrm{OPN}-32 \mathrm{kDa}$ ) was expressed in $\mathrm{HO}-$ 8910PM cells (Figure 1E). This OPN segment contains only the CD44/CD44v-binding domain digested by thrombin or MMP-2/MMP-7 at the hypersensitive site in the SVVYGLR sequence.

\section{Effect of TLR4 on proliferation and metastatic potential of ovarian cancer cells}

The MTT assay was used to test in vitro proliferation activity of tumor cells. Without LPS stimulation, the proliferation activity of tumor cells increased during $12 \mathrm{~h}$. The cell proliferation significantly changed by LPS stimulation, and the maximum absorbance value at $429 \mathrm{~nm}$ was present after $6 \mathrm{~h}$, with a proliferation rate of approximately $137.1 \%$ compared to cells without stimulation (Figure 2A-2B). To investigate the effect of TLR4 signal block on cell proliferation, the TLR4 inhibitor TAK-242 was used. The LPS-stimulated increase in the proliferation of tumor cells was significantly reduced with TAK-242 pretreatment, whereas no significant change was observed in cells treated with TAK-242 alone (Figure 2C). These results further confirm that the proliferation of HO-8910PM cells is facilitated through the TLR4 signal activated by LPS.

Anchorage-independent growth is the ability of cancer cells to grow independently of a substrate, which reflects the proliferation potential of individual cells. Soft agar colony formation test was performed to measure the effect of TLR4 on anchorage-independent growth potential of HO-8910PM cells, and the results were similar to that of cell proliferation activity. The ability of tumor cells to form clones in soft agar was significantly enhanced after LPS stimulation, compared to non-LPS-stimulated cells. The clone formation rate was significantly decreased by TAK-242 treatment, compared to LPS treated cells (Figure 2D-2E).

The wound healing assay can be used to investigate cell polarity and matrix reconstruction and evaluate cell migration ability. The wound healing rate of HO-8910PM cells, which is positively correlated with cell migration ability, was significantly increased by LPS stimulation. TAK-242 treatment did not significantly affect cell migration with or without LPS stimulation (Figure 3A3B). A chemotaxis chamber enveloped with extracellular 
matrix was used to test the invasion activity of HO8910PM cells treated with LPS and/or TAK-242. It was found that the cell invasion was significantly enhanced by LPS stimulation, whereas no significant change was observed in cells treated with TAK-242 alone. However, the increased invasion ability of the LPS-stimulated cells was significantly reduced after pretreatment with TAK242 (Figure 3C-3D).

\section{Effect of OPN on proliferation and metastatic potential of ovarian cancer cells}

To determine whether secreted OPN affects cell proliferation, we performed an MTT assay after blocking the secreted OPN in HO-8910PM cells with an OPN neutralizing antibody, Ab8448. Proliferative activity was not significantly inhibited after treatment with the neutralizing antibody, although there was modest inhibition when the OPN antibody was added after LPS pretreatment (Figure 4A). In the wound healing assay, cell migration was enhanced following LPS stimulation, which could be inhibited by Ab8448 (Figure 4B-4C).

Given that the in vitro invasion activity of HO8910PM cells was significantly enhanced by LPS stimulation, we questioned whether treatment with Ab8448 impairs this phenotype. We found that invasion activity of HO-8910PM cells with or without LPS stimulation could both be inhibited by blocking OPN with Ab8448 (Figure 4D-4E).
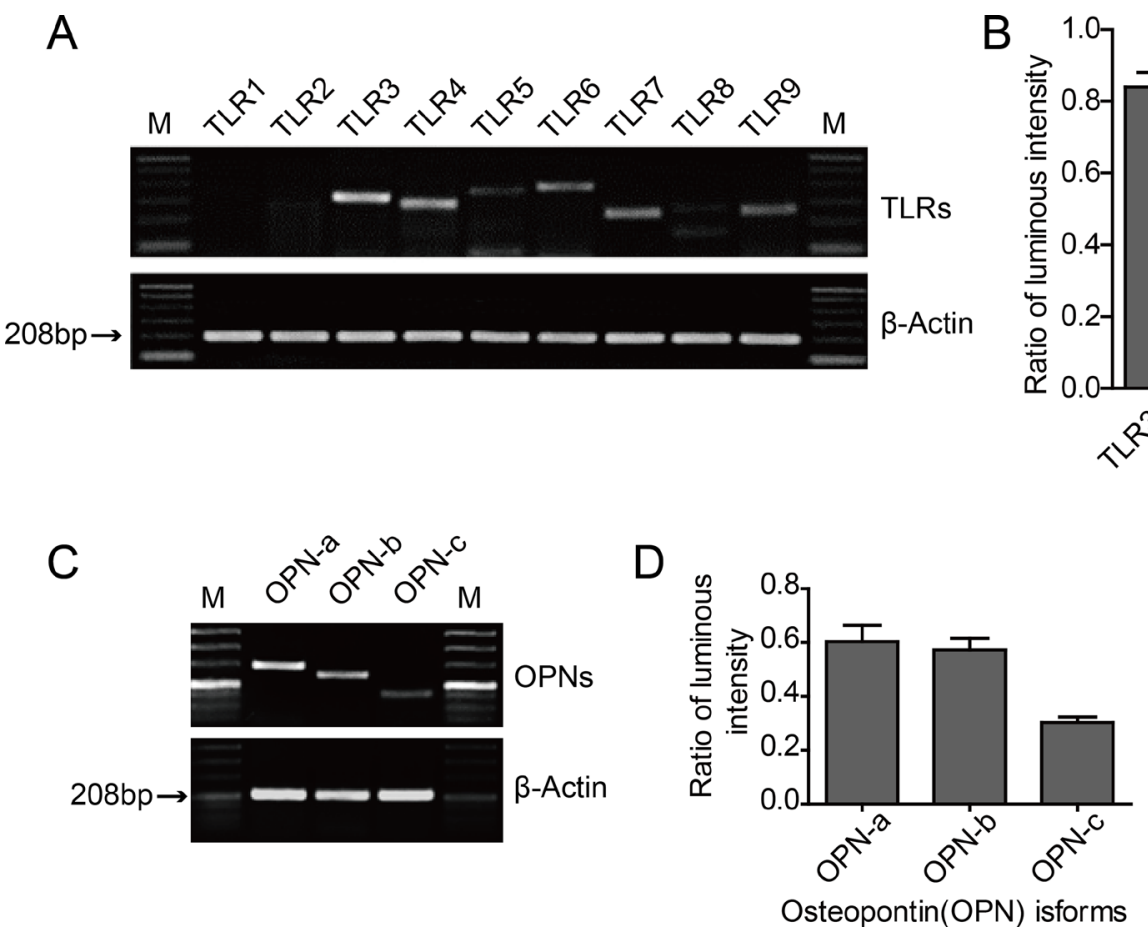

\section{Effect of TLR4 on OPN mediated metastatic phenotype of ovarian cancer cells}

Expression of OPN-a in HO-8910PM cells was rapidly up-regulated and peaked 2 hours after LPS stimulation. Compared with the non-stimulated group, the LPS-stimulated group exhibited a 10-fold up-regulation of OPN-a expression. Four hours after LPS stimulation, the expression of OPN-b was up-regulated 15-fold compared with that in the non-stimulated group. OPN-c expression was rapidly up-regulated 60 -fold 2 hours after LPS stimulation. Subsequently, as the stimulation reduced and the degradation increased, mRNA levels of the three OPN isoforms decreased gradually (Figure 5A). To confirm whether the activation of TLR4 affected the OPN expression, the variation in the expression of secreted OPN in the supernatant of HO-8910PM cells before and after LPS stimulation was tested via immunoblotting. The protein levels of OPN-a, OPN-b, and OPN-c were all upregulated at various extents after LPS stimulation, and the expression of OPN-32kDa was also significantly increased (Figure 5B). Overall, the OPN expression in ovarian cancer cells is significantly up-regulated by the activation of TLR4 via LPS stimulation.

To explore the association between TLR4 signal pathway and OPN, as well as the possible mechanism that OPN promoted the metastasis phenotype of ovarian cancer cells, we used RNAi to knockdown OPN in HO-8910PM cells. In the wound healing assay and in vitro invasion

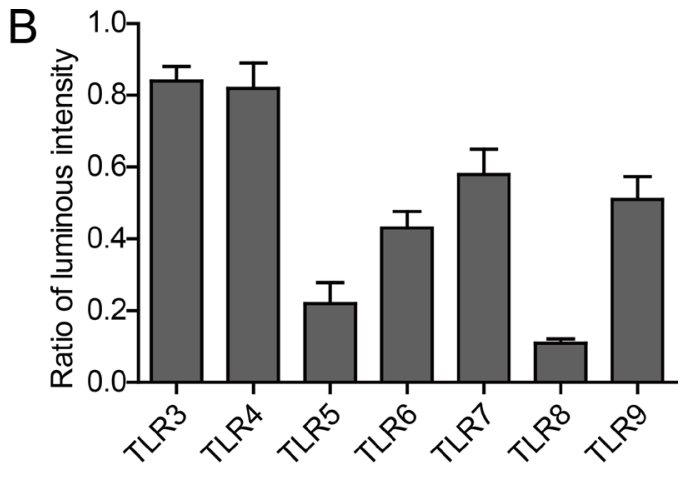

Toll like receptors(TLRs)

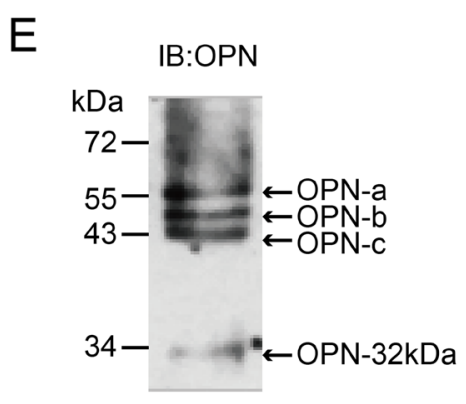

Figure 1: Expression of TLRs and OPN isoforms in HO-8910PM cells. (A) mRNA expression of various TLRs analyzed by RT-PCR. M: Marker. (B) Luminous intensity ratios of TLRs to $\beta$-actin. (C) mRNA expression of OPN isoforms OPN-a, -b and -c analyzed by RT-PCR. (D) Luminous intensity ratios of OPN isoforms to $\beta$-actin. (E) Expression of OPN protein measured by immunoblotting (IB) on cell supernatants. (A-E) Data are shown as mean $\pm \mathrm{SD}$ of three independent experiments. 
assay of MC (HO-8910PM) and MI (HO-8910PM with OPN knockdown) cells, migration and invasion of MI cells was reduced compared to MC cells. Following LPS stimulation, migration and invasion of both $\mathrm{MC}$ and MI cells were significantly increased, but the extent of increase was reduced in MI cells compared to MC cells (Figure 6A-6D), suggesting that OPN is necessary for optimal LPS-stimulated migration and invasion. Thus, the metastatic ability of ovarian cancer cells is promoted by TLR4 activation via the up-regulation of OPN expression.

Using ELISA and immunofluorescence to measure expression of OPN, we found it was significantly less in MI cells than that in MC cells, which increased following LPS stimulation. However, the extent of increase in MI cells was less than that in MC cells (Figure 6E-6F). These results demonstrate that the proliferation and metastasis of ovarian cancer cells are facilitated by TLR4 via the up-regulation of OPN expression. Thus, the up-regulation of OPN expression by TLR4 signal may be an important factor that could enhance proliferation and metastasis ability of cancer cells.

\section{DISCUSSION}

Several studies have shown that the expression of TLR4 is associated with ovarian cancer progression, treatment resistance, and poor prognosis [27-30]. In this study, we found a high expression level of TLR4 in the human ovarian cancer cell line (HO-8910PM), suggesting that TLR4 elicited essential biological functions and could be used as a potential target for the immune treatment of cancer. Therefore, the effect of TLR4 on the proliferation and metastasis of ovarian cancer cells was studied and it was found that the proliferation, anchorage-independent growth, migration and invasion abilities are significantly increased after stimulation with LPS. These effects are TLR4 specific as treatment with a TLR4 inhibitor abrogates this phenotype. Taken together, activation of TLR4 signal pathway can enhance the proliferation and metastatic ability of ovarian cancer cells, which directly promotes a malignant metastatic phenotype.

OPN has been reported overexpressed in various cancers, and is regarded as a novel cancer marker [31-34]. OPN can be produced via secretion by malignant tumor cells and promotes self-adhesion, invasion, metastasis, neovascularization and new tumor formation [35, 36]. Kang et al. found that OPN increased the invasion of lung cancer cells by triggering ROCK signaling mediated by the FAK/PI3K/AKT pathway [37]. Song et al. demonstrated that OPN derived from tumor microenvironment could promote metastasis of hepatocellular carcinoma [38]. Shevde et al. reported that OPN was an effector of critical steps in tumor progression and metastasis, particularly in facilitating bone metastasis of breast cancer [39]. Our research findings are consistent with previous studies. The OPN splicing isoforms OPN-a, OPN-b, OPN-c, and
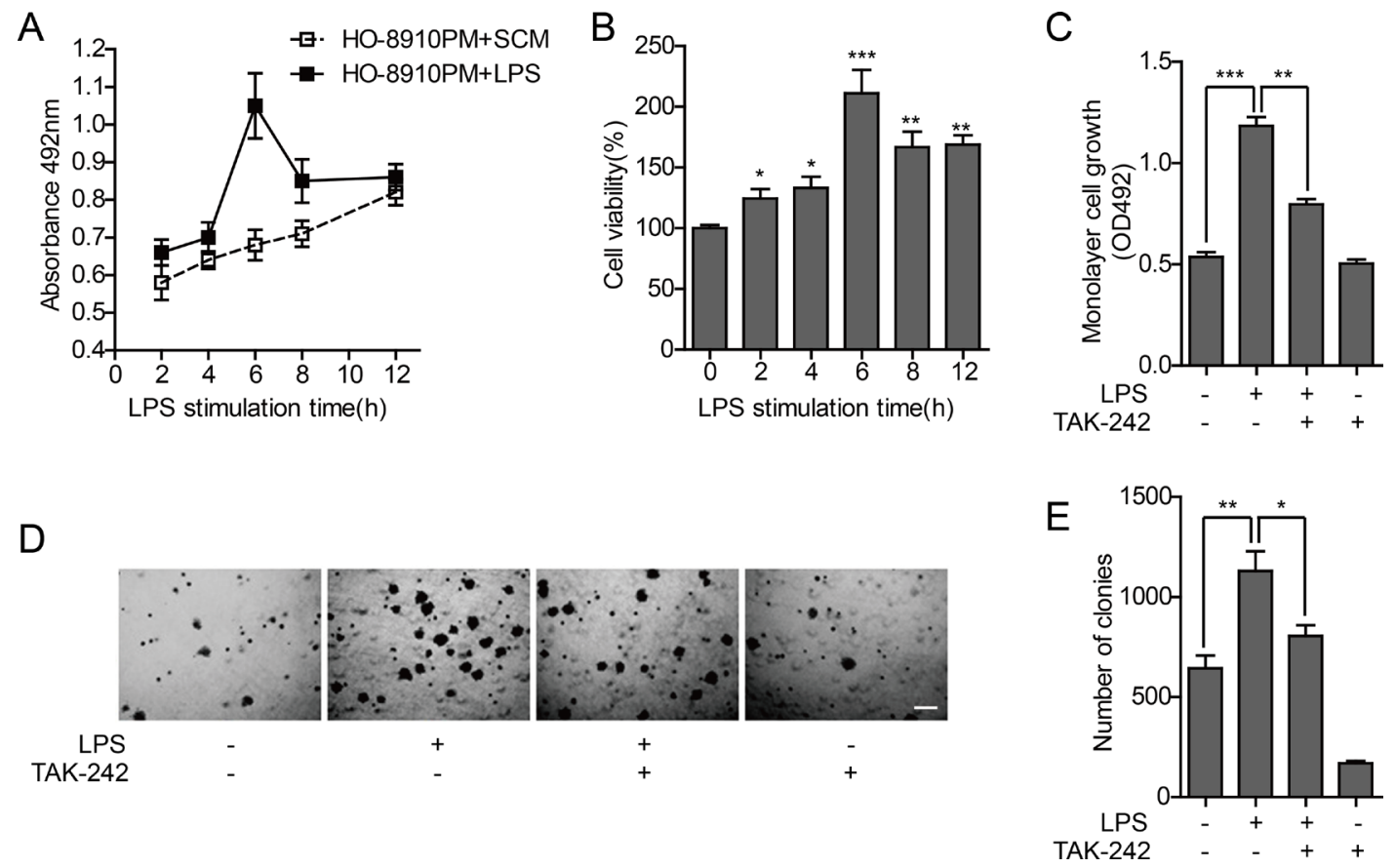

Figure 2: Effect of TLR4 on proliferation ability of HO-8910PM cells. (A) Monolayer cell growth rates measured by MTT assay in cells treated with serum-containing medium (SCM) or LPS at indicated times. (B) Quantification of cell proliferation based on assay in (A). (C) Monolayer cell growth rates measured by MTT assay in cells treated with LPS and/or TAK-242. (D) Inverted microscopic images of cells treated with LPS and/or TAK-242 in colony formation assay at low magnification (Scale bar: $100 \mu \mathrm{m})$. (E) Colony numbers were counted using ImageJ software. (A-E) Data are shown as mean $\pm \mathrm{SD}$ of three independent experiments. ${ }^{*} P<0.05 ;{ }^{* * *} P<0.01 ;{ }^{* * *}$ $P<0.001$. 
OPN-32kDa were highly expressed in HO-8910PM cells. LPS stimulation significantly improved the proliferation, migration and invasion abilities of tumor cells, but these effects were significantly reduced after the secreted OPN was neutralized. These results indicate that OPN boosts tumor cell proliferation, migration and invasion, and further suggest that the LPS-induced aggravation of metastatic phenotype is mediated by OPN. Therefore, OPN has considerable potential as a tumor metastatic gene for the diagnosis and treatment of tumors. However, the study on OPN is still premature. If OPN and its receptors can be further disrupted from gene initiation to signal transduction, and the tumor invasion pathway can be blocked, the extent of cancer malignancy will be effectively reduced in the future.

Moreover, we found that OPN expression was upregulated through the activation of TLR4 in HO-8910PM cells, which exacerbated the metastatic phenotype. When OPN expression was knocked down, the cancer cell proliferation and metastasis induced by LPS was significantly reduced. Thus, up-regulation of OPN expression following TLR4 activation was an important factor that facilitated the malignant metastasis of ovarian cancer cells. However, the possible molecular mechanism that TLR4 regulates OPN remains unclear. TLR4 induces inflammatory gene expression and contributes to the formation of inflammatory microenvironments, which promotes cancer development and metastasis [40-42]. TLR4 leads to the activation of mitogen-activated protein kinase (MAPK) and nuclear factor-kappa B (NF- $\mathrm{B})$, resulting in the secretion of pro-inflammatory cytokines as well as the induction of matrix metalloproteinases (MMPs) [43]. Furthermore, several studies reported that OPN enhanced the migration and invasion of cancer cells by up-regulating MMP-2 and MMP-9 activities via NF- $\kappa \mathrm{B}$ pathway [44-47]. In this context, it has been indicated that $\mathrm{NF}-\kappa \mathrm{B}$ may be a key factor between TLR4 signaling and OPN/MMP axis. Further research should be conducted to clarify this mechanism.

In conclusion, osteopontin, induced by LPS stimulation, enhances proliferation and metastasis of ovarian cancer cells. Our study provides a theoretical basis for the mechanisms of tumorigenesis, development and metastasis, and TLR4 and OPN may serve as potential combined targets for future therapy of ovarian cancer.

\section{MATERIALS AND METHODS}

\section{Cell culture}

The human ovarian cancer cell line HO-8910PM was purchased from the Institute of Biochemistry and
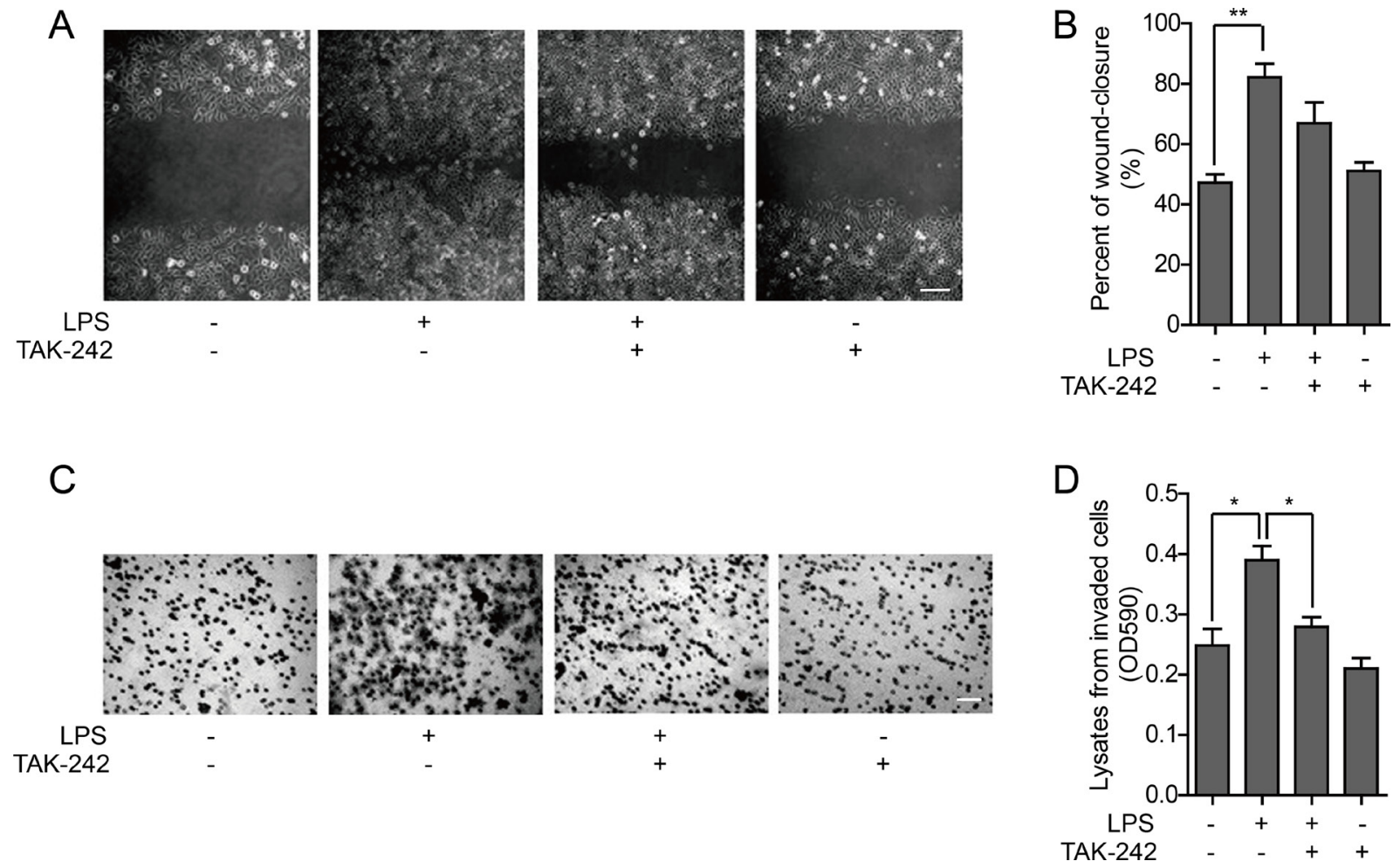

Figure 3: Effect of TLR4 on metastatic ability of HO-8910PM cells. (A) Wound healing images of cells treated with LPS and/ or TAK-242 at low magnification (Scale bar: $100 \mu \mathrm{m})$. (B) The wound-closure rates (\%) were generated from the wound scale ratio as described in Materials and Methods. (C) Microscope images of cells treated with LPS and/or TAK-242 in cell invasion assay (Scale bar: $100 \mu \mathrm{m}$ ). (D) The cell invasion rates were evaluated as described in Materials and Methods. (A-D) Data are shown as mean \pm SD of three independent experiments. ${ }^{*} P<0.05 ;{ }^{* *} P<0.01$. 
Cell Biology (Shanghai, China). Cells were cultured in RPMI-1640 medium (Invitrogen, Shanghai, China), supplemented with 10\% fetal bovine serum (Gibco, Carlsbad, CA, USA), $100 \mathrm{U} / \mathrm{ml}$ Penicillin (Invitrogen) and $100 \mathrm{U} / \mathrm{ml} \mathrm{Streptomycin} \mathrm{(Invitrogen).} \mathrm{Cells} \mathrm{were}$ maintained at $37^{\circ} \mathrm{C}$ in a humidified atmosphere of $5 \%$ $\mathrm{CO}_{2}$.

\section{RNA isolation and reverse transcription-PCR}

HO-8910PM cells in logarithmic phase were seeded at $2.0 \times 10^{5}$ cells $/ \mathrm{ml}$. Total RNA was isolated using RNAiso Plus kit (TakaRa, Dalian, China) according to the manufacturer's instructions. The concentration was adjusted to $1 \mu \mathrm{g} / \mu \mathrm{l}$.

Reverse transcription was done by M-MLV Reverse Transcriptase system (Promega, Madison, WI, USA) according to the manufacturer's instructions, and PCR was performed using $\beta$-actin as an internal control. The primers were designed by Primer Premier 5.0 software (Table 1). A series of pre-experiments under the same conditions with gradient cycle numbers were performed to confirm the plateau phase, then the optimal cycle number just lower than the number of plateau phase was chosen as the exponential phase. PCR settings were the following: denaturation at $94^{\circ} \mathrm{C}$ for $3 \mathrm{~min}$, followed by 30 cycles of $94^{\circ} \mathrm{C}$ for $30 \mathrm{~s}$, annealing at $55-60^{\circ} \mathrm{C}$ for $30 \mathrm{~s}$, and $72^{\circ} \mathrm{C}$ for $90 \mathrm{~s}$, with a final extension step of $72^{\circ} \mathrm{C}$ for $7 \mathrm{~min}$. The relative quantities of mRNA were analyzed by Band Scan 5.0 software.

\section{MTT assay}

HO-8910PM cells were seeded in 96-well plates $\left(2.0 \times 10^{4}\right.$ cells/well). After $12 \mathrm{~h}$ of incubation, experimental group was stimulated with $0.1 \mu \mathrm{g} / \mathrm{ml}$ LPS (Sigma, Santa Clara, CA, USA) dissolved in Phosphate Buffered Saline (PBS), while LPS was replaced by serum-containing medium in control group. The proliferation assay was done with 3 - (4, 5 - dimethylthiazol - 2 - ylx $)$ - 2, 5 diphenyltetrazolium bromide (MTT). $200 \mu \mathrm{l}$ of $0.5 \mathrm{mg} /$ $\mathrm{ml}$ MTT was added to the medium, and the cells were incubated at $37^{\circ} \mathrm{C}$ for $4 \mathrm{~h}$. Then the culture medium was discarded and $150 \mu \mathrm{l}$ DMSO (Invitrogen) was added to each well to dissolve the precipitate. The OD at $492 \mathrm{~nm}$ was measured at indicated time periods $(0 \mathrm{~h}, 2 \mathrm{~h}, 4 \mathrm{~h}, 6 \mathrm{~h}$, 8 h, 12 h) after stimulation using the Microplate Reader (Rayto, Shenzhen, China).

In seperate experiments, cells were divided into four groups: the control group (C) and LPS group (L) were pretreated with serum-containing medium, while the inhibitor group (I) and inhibitor+LPS group (I+L)

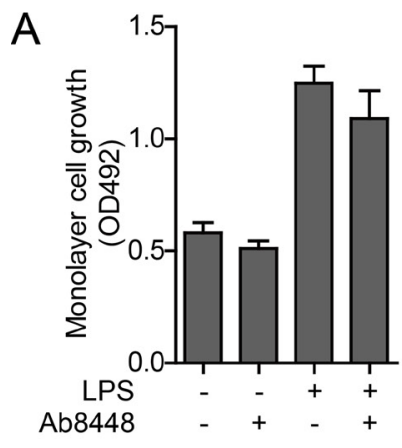

B
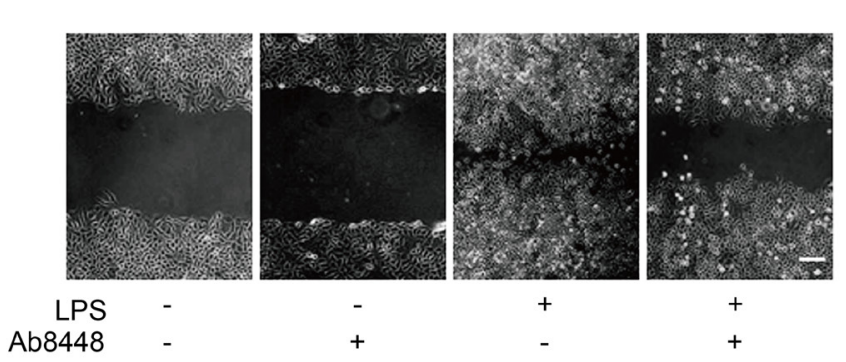

D
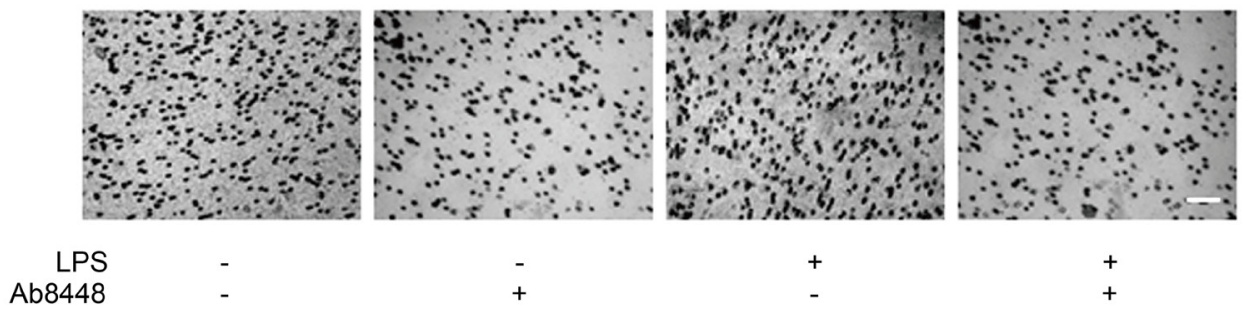
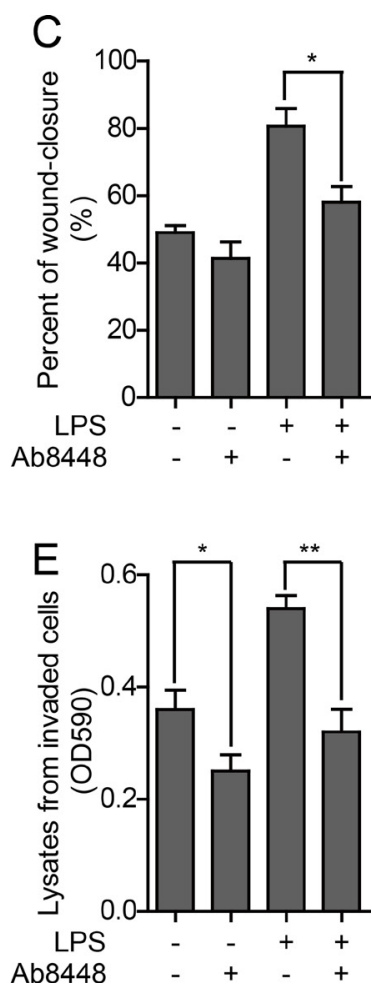

Figure 4: Effect of OPN on proliferation and metastatic ability of HO-8910PM cells. (A) Cell proliferation ability was measured by MTT assay in cells with or without OPN neutralizing antibody Ab8448. (B) Inverted microscopic images of cells treated with LPS and/or Ab8448 in wound healing assay (Scale bar: $100 \mu \mathrm{m})$. (C) The wound-closure rates (\%) were generated from the wound scale ratio as described in Materials and Methods. (D) Microscope images of cells treated with LPS and/or Ab8448 in cell invasion assay (Scale bar: $100 \mu \mathrm{m}$ ). (E) The cell invasion rates were evaluated as described in Materials and Methods. (A-E) Data are shown as mean \pm SD of three independent experiments. ${ }^{*} P<0.05 ;{ }^{* *} P<0.01$. 
Table 1: Primers used for RT-PCR

\begin{tabular}{|c|c|c|c|c|}
\hline \multirow{2}{*}{ Genes name } & \multirow{2}{*}{ ACC. NO. } & \multicolumn{2}{|c|}{ Primer sequences } & \multirow{2}{*}{$\begin{array}{l}\text { Amplification } \\
\text { length(bp) }\end{array}$} \\
\hline & & Forward (5' to $3^{\prime}$ ) & Backward(5' to $\left.3^{\prime}\right)$ & \\
\hline TLR1 & NM_003263.3 & TTTGAAAATTGTGGGCACCTTACTG & AAGCAACATTGAGTTCTTGCAAAGC & 337 \\
\hline TLR2 & NM_003264.3 & TGTGAACCTCCAGGCTCTG & GTCCATATTTCCCACTCTCAGG & 256 \\
\hline TLR3 & NM_003256.1 & AGCCGCCAACTTCACAAG & AGCTCTTGGAGATTTTCCAGC & 327 \\
\hline TLR4 & NM_138554.3 & ACAGAAGCTGGTGGCTGTG & TCTTTAAATGCACCTGGTTGG & 291 \\
\hline TLR5 & NM_003268.5 & CATGACCATCCTCACAGTCACAAAG & GGGCATAACTGAAGGCTTCAAGG & 365 \\
\hline TLR6 & NM_006068.3 & CATGACGAAGGATATGCCTTCTTTG & TATTGACCTCATCTTCTGGCAGCTC & 382 \\
\hline TLR7 & NM_016562.3 & TTGGCTTCTGCTCAAATGC & CTAAAGGTTGGAATTCACTGCC & 300 \\
\hline TLR8 & NM_138636.4 & GTCGACTACAGGAAGTTCCCC & GGGTAACTGGTTGTCTTCAAGC & 260 \\
\hline TLR9 & NM_017442.2 & GTGCCCCACTTCTCCATG & GGCACAGTCATGATGTTGTTG & 260 \\
\hline OPN-a & NM_001040058.1 & CCTAGCCCCACAGAATGC & GGGACAACTGGAGTGAAAAC & 291 \\
\hline OPN-b & NM_000582.2 & CCTAGCCCCACAGACCCTT & GGGGACAACTGGAGTGAAAAC & 250 \\
\hline OPN-c & NM_001040060.1 & GAAAAGCAGAATGCTGTGTCCT & CAGAGTCGTTCGAGTCAATGG & 160 \\
\hline$\beta$-actin & NM_001101.3 & GCCGTCTTCCCTCCATCGTG & GGAGCCACACGCAGCTCATTGTAGA & 208 \\
\hline
\end{tabular}

were pretreated with $1 \mu \mathrm{g} / \mathrm{ml}$ TLR4 inhibitor TAK-242 (Invitrogen) instead. After $6 \mathrm{~h}$ of pretreatment at $37^{\circ} \mathrm{C}$, culture medium was discarded in all groups. Then serumfree medium was added to C and I group, LPS (Sigma) was added to $\mathrm{L}$ and $\mathrm{I}+\mathrm{L}$ group. All the groups were maintained in culture for another $6 \mathrm{~h}$. MTT assay was performed as described above.

\section{Colony formation in soft agar}

In colony formation assay, the $35 \mathrm{~mm}$ dishes were coated with $1.5 \mathrm{ml}$ of base layer containing $0.5 \%$ of agar prepared with serum-containing medium. HO-8910PM cells in logarithmic phase were grouped and treated as described in MTT assay. Subconfluent cells were trypsinized and counted, adjusting to $1.0 \times 10^{4} \mathrm{cells} / \mathrm{ml}$, and then resuspended in serum-containing medium plus $20 \%$ fetal bovine serum (Gibco) and $0.7 \%$ agar. $3 \mathrm{ml}$ of the agar-cell mixture was plated over the $1.5 \mathrm{ml}$ base layer to make the top agar. After 14 days of incubation in growth medium, colonies were stained with crystal violet and photographed under inverted light microscope (Olympus, Tokyo, Japan). Total colonies per dish were counted using ImageJ software.

\section{Wound healing assay}

HO-8910PM cells were seeded in $35 \mathrm{~mm}$ dishes at $2.0 \times 10^{5}$ cells $/ \mathrm{ml}$ and allowed to grow until confluence. The same grouping and pretreatment was performed as described above. After $24 \mathrm{~h}$ of incubation with mitomycin, the cell monolayer was scratched with a pipette tip (200

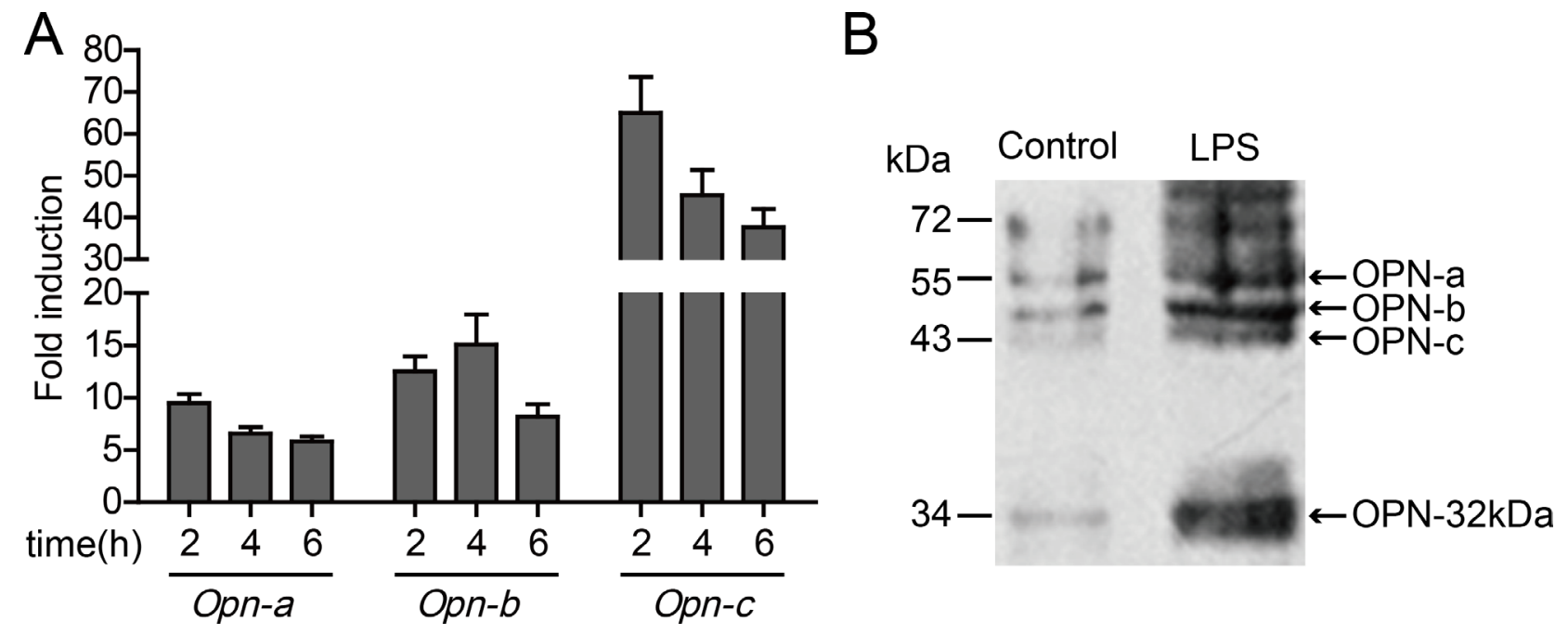

Figure 5: Effect of TLR4 on OPN expression in HO-8910PM cells. (A) mRNA levels of OPN isoforms were analyzed by realtime PCR at indicated times after LPS stimulation. The amount of mRNA in untreated cells was given a value of 1.0. (B) The protein levels of OPN isoforms before and after LPS stimulation were measured by immunoblotting. (A-B) Data are shown as mean \pm SD of three independent experiments. 
$\mu l)$ to create a narrow wound-like gap. Shortly after wounding, the cells were washed with serum-free medium and incubated with serum-containing medium. The dishes were photographed at $0 \mathrm{~h}, 6 \mathrm{~h}, 12 \mathrm{~h}, 24 \mathrm{~h}, 48 \mathrm{~h}$ and $72 \mathrm{~h}$ using an inverted light microscope (Olympus). The wound spacing is measured using ImageJ software, and the wound-closure rate (\%) was calculated using the following formula: Wound-closure rate $\%=1-\mathrm{S}_{\text {treated }} / \mathrm{S}_{\text {control }} \times 100 \%$, where $\mathrm{S}_{\text {treated }}$ and $\mathrm{S}_{\text {control }}$ were the average wound spacing of three independent experiments from treated and control groups, respectively.

\section{Cell invasion assay}

In vitro invasiveness was assayed using 24-well transwell chambers with polycarbonate membrane (Corning, New York, NY, USA) coated by $100 \mu$ l matrigel
(BD, San Jose, CA, USA). Matrigel was diluted three times with cold serum-free PRMI-1640 medium, applied to the membrane, cultured at least $4-5$ hours at $37^{\circ} \mathrm{C}$, and rehydrated with serum-free medium. HO-8910PM cells were grouped and pretreated as above. $100 \mu \mathrm{l}$ of cell suspension $\left(5.0 \times 10^{5}\right.$ cells $\left./ \mathrm{ml}\right)$ was seeded to the upper chamber, and the lower chamber was filled with $0.6 \mathrm{ml}$ culture medium plus $10 \% \mathrm{FBS}$. After incubation at $37^{\circ} \mathrm{C}$ for $24 \mathrm{~h}$, matrigel and cells that had not invaded were wiped off the upper surface of membrane with a cotton swab. The upper chambers were removed and inverted, drying in the air. Cells on the lower surface of membrane were stained with $500 \mu \mathrm{l}$ of $0.1 \%$ crystal violet and examined microscopically. Four randomly chosen fields were photographed and counted to determine the cell numbers that had invaded through the membrane. Furthermore, the membranes were put into other 24-
A

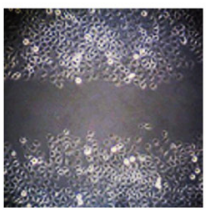

$\mathrm{MC}$

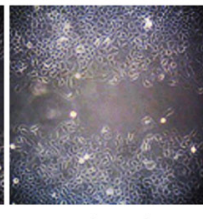

MC-LPS

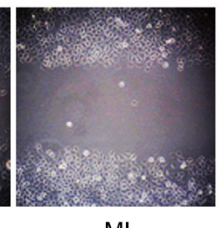

MI

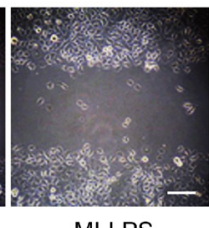

MI-LPS

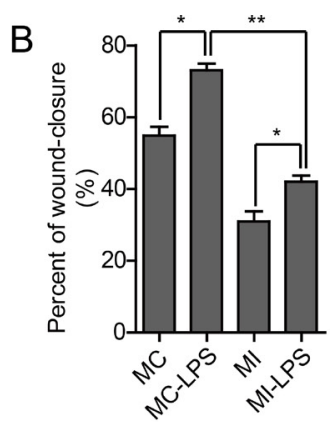

D

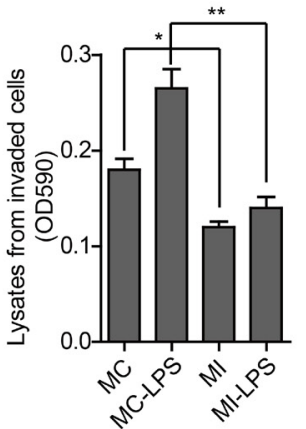

$\mathrm{E}$

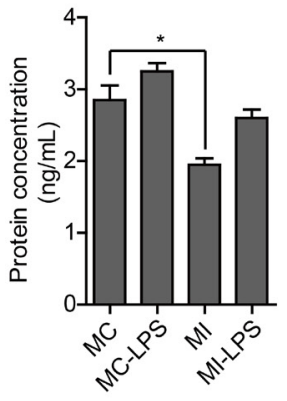

$\mathrm{F}$

$\mathrm{MC}$
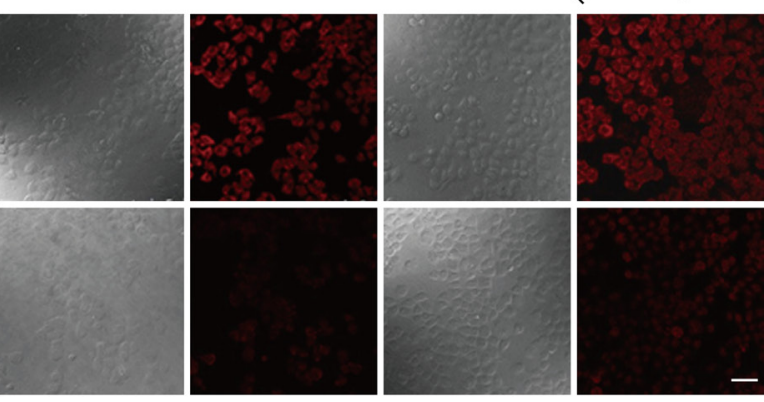

LPS

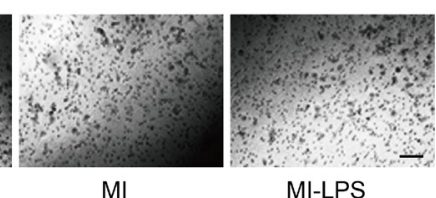

Figure 6: Effect of TLR4 in HO-8910PM cells with OPN knockdown. (A) Inverted microscopic images of MC and MI cells in wound healing assay (Scale bar: $100 \mu \mathrm{m})$. (B) The wound-closure rates (\%) were generated from the wound scale ratio as described in Materials and Methods. (C) Inverted microscopic images of MC and MI cells in cell invasion assay (Scale bar: $100 \mu \mathrm{m})$. (D) The cell invasion rates (\%) were evaluated as described in Materials and Methods. (E) OPN protein levels in MC and MI cells were measured by ELISA according to the human OPN standard curve (not shown). (F) OPN expression (red) in MC and MI cells was analyzed by immunofluorescence. (A-F) MC: untreated HO-8910PM cells; MC-LPS: LPS-treated MC cells; MI: untreated HO-8910PM cells with OPN knockdown; MI-LPS: LPS-treated MI cells. Data are shown as mean $\pm \mathrm{SD}$ of three independent experiments. ${ }^{*} P<0.05 ;{ }^{* *} P<0.01$. 
well plates containing $500 \mu \mathrm{l}$ of $33 \%$ acetic acid. After $10 \mathrm{~min}$ of oscillation and dissolution, the OD of lysates from invaded cells was measured at $570 \mathrm{~nm}$ using the Microplate Reader (Rayto).

\section{OPN neutralizing assay}

HO-8910PM cells were pretreated with LPS $(0.1 \mu \mathrm{g} /$ $\mathrm{ml})$ for $6 \mathrm{~h}$, and seeded in 96-well plates $\left(2.0 \times 10^{4}\right.$ cells $/$ well). After $7 \mathrm{~h}$ of incubation, OPN neutralizing antibody ab8448 (Abcam, Cambridge, MA, USA) was added to the culture medium with a final concentration of $200 \mu \mathrm{g} / \mathrm{ml}$. Cells were incubated in culture for another $12 \mathrm{~h}$, and then MTT assay, colony formation in soft agar, wound healing assay and cell invasion assay were performed under the same conditions as previously described.

\section{Immunoblotting}

HO-8910PM cells in logarithmic phase were lysed with $200 \mu$ lysis buffer [50 mM Tris- $\mathrm{HCl}$ (pH 7.5), 150 $\mathrm{mM} \mathrm{NaCl}, 1 \%$ Tween-20, 0.2\% NP-40, 10\% glycerol, 10 $\mathrm{mM} \mathrm{NaF}$ and $1 \mathrm{mM} \mathrm{Na}_{3} \mathrm{VO}_{4}$ supplemented with protease inhibitor cocktail]. Total protein concentration was measured using Coomassie brilliant blue staining. $40 \mu \mathrm{g}$ of protein was loaded onto a 10\% SDS-polyacrylamide gel, separated by electrophoresis and electroblotted onto a polyvinylidene difluoride (PVDF) membrane (Osmonics, Pittsburgh, PA, USA). The membranes were blocked with 5\% defatted dry milk (Roche, Basel, Switzerland) for $2 \mathrm{~h}$ at $37^{\circ} \mathrm{C}$ and probed with rabbit antiOPN antibody (1:4 000 dilution, Abcam) for $2 \mathrm{~h}$ at room temperature. After washing with TBST (20 mM Tris$\mathrm{HCl}, 140 \mathrm{mM} \mathrm{NaCl}, 0.1 \%$ Tween-20), the membranes were subsequently incubated with the secondary antibody (1:8 000 dilution, Beyotime, Haimen, China) conjugated with horseradish peroxidase for another $1 \mathrm{~h}$ at room temperature. The immunoreactivity was visualized by enhanced chemiluminescence (ECL) system (Beyotime) and exposed to an X-ray film.

\section{Real-time PCR}

Real-time PCR of TLR4 and OPN was performed using SYBR Green RealMasterMix (Invitrogen) according to the manufacturer's instructions, with a Rotor-Gene Q Real-time PCR instrument (Qiagen, Hilden, Germany). The primers used in this study were shown in Table 2, using $\beta$-actin as an internal control. The amplification scheme was: incubation for $5 \mathrm{~min}$ at $95^{\circ} \mathrm{C}$, followed by 40 cycles of $10 \mathrm{~s}$ at $95^{\circ} \mathrm{C}, 15 \mathrm{~s}$ at $59^{\circ} \mathrm{C}$ and $20 \mathrm{~s}$ at $72^{\circ} \mathrm{C}$, with a final extension step of $7 \mathrm{~min}$ at $72^{\circ} \mathrm{C}$. Data were normalized to $\beta$-actin expression in each sample. In all cases, each PCR was performed with triplicate samples. Relative expression of mRNA was determined using the $2^{(-\Delta \Delta \mathrm{Ct})}$ method.

\section{RNA Interfering and transfection}

HO-8910PM cells were cultured at $5.0 \times 10^{5}$ cells/ $\mathrm{ml}$ in RPMI-1640 medium containing 10\% FBS until 40\% to $70 \%$ confluent. Then cells were transfected with GFP expressing plasmids pGPU6/GFP/Neo containing shRNA specifically targeting OPN or negative control shRNA, which were pre-designed with the following sequences: OPN sense, 5'-CACCGCAGCTTTACAACAAA TACTTCAAGAGAGTATTTGTTGTAAAGCTGCTTTT TTG-3' and antisense, 3'-CGTCGAAA TGTTGTTTATGAAGTTCTCTCATAAACAACATTTCG ACGAAAAAACCTAG-5'; negative control sense, 5'-CACCGTTCTCCGAACGTGTCACGTCAAGAGA TTACGTGACACGTTCGGAGAATTTTTTG-3' and antisense, 3'-CAAGAGGCTTGCCTCTTAAAAAA CCAG-5'. shRNA and plasmids were obtained from GenePharma (Shanghai, China). Cell transfection was carried out with Lipofectamine 2000 reagent (Invitrogen) in accordance with the manufacturer's instructions. After transfection, HO-8910PM cells were used for MTT assay, wound healing assay and cell invasion assay as described above.

\section{ELISA}

Transfected cells were plated in $35 \mathrm{~mm}$ dishes at 1.0 $\times 10^{6}$ cells/dish in $1 \mathrm{~mL}$ of serum-free medium and treated with or without LPS. The supernatants were collected, and enzyme-linked immunosorbent assay (ELISA) was used to measure OPN expression levels according to the manufacturer's protocols of OPN ELISA kits (Invitrogen).

\section{Immunofluorescence}

Transfected cells grown on glass coverslips were fixed for $30 \mathrm{~min}$ in $4 \%$ paraformaldehyde and permeabilized with $0.5 \%$ Triton X-100 (Promega) in PBS buffered saline for $30 \mathrm{~min}$. After washing with TBS-0.1\% Triton X-100 (TBSTx), nonspecific binding sites were blocked with TBSTX-5\% BSA (Roche) for $60 \mathrm{~min}$. Then cells were applied sequentially with a 1:100 dilution of rabbit polyclonal antibody anti-OPN (Abcam) at $4{ }^{\circ} \mathrm{C}$ overnight and a 1:200 dilution of $\mathrm{Cy} 3$-conjugated goat anti-rabbit $\operatorname{IgG}$ (Beyotime) at room temperature for $60 \mathrm{~min}$ in the dark. For negative control, PBS was added instead of primary antibody. Further, immunofluorescence was visualized under a laser-scanning confocal microscope (Zeiss, Oberkochen, Germany).

\section{Statistical analysis}

All data in different experiments were processed by SPSS 13.0 and expressed as mean \pm SD. The data shown were obtained from at least 3 independent experiments. Differences between data groups were evaluated for 
Table 2: Primers used for real-time PCR

\begin{tabular}{|c|c|c|c|c|}
\hline \multirow{2}{*}{$\begin{array}{l}\text { Genes } \\
\text { name }\end{array}$} & \multirow[t]{2}{*}{ ACC. NO. } & \multicolumn{2}{|c|}{ Primer sequences } & \multirow{2}{*}{$\begin{array}{c}\text { Amplification } \\
\text { length(bp) }\end{array}$} \\
\hline & & Forward (5' to 3') & Backward(5' to 3') & \\
\hline TLR4 & NM_138554.3 & AAGATTACCAGCCGCCAA & GTAGATGACAAGCCATTATGAGAC & 255 \\
\hline $\mathrm{OPN}-\mathrm{a}$ & NM_001040058.1 & CCTAGCCCCACAGAATGC & GGGACAACTGGAGTGAAAAC & 291 \\
\hline OPN-b & NM_000582.2 & CCTAGCCCCACAGACCCTT & GGGGACAACTGGAGTGAAAAC & 250 \\
\hline OPN-c & NM-001040060.1 & GAAAAGCAGAATGCTGTGTCCT & CAGAGTCGTTCGAGTCAATGG & 160 \\
\hline$\beta$-actin & NM_001101.3 & CCTGTACGCCAACACAGTGC & ATACTCCTGCTTGCTGATCC & 211 \\
\hline
\end{tabular}

significance using Student $t$-test. Statistical significance was represented as ${ }^{*} P<0.05,{ }^{* *} P<0.01,{ }^{* * *} P<0.001$.

\section{ACKNOWLEDGMENTS AND FUNDING}

This work was supported by the Shandong Provincial Natural Science Foundation of China (ZR2011HZ004) and the Project of Shandong Province Higher Educational Science and Technology Program (J10LC21 and J16LE07).

\section{CONFLICTS OF INTEREST}

The authors declare no conflicts of interest.

\section{REFERENCES}

1. Mifsud EJ, Tan AC, Jackson DC. TLR Agonists as modulators of the innate immune response and their potential as agents against infectious disease. Front Immunol. 2014; 5:79.

2. Brubaker SW, Bonham KS, Zanoni I, Kagan JC. Innate immune pattern recognition: a cell biological perspective. Annu Rev Immunol. 2015; 33:257-290.

3. Rakoff-Nahoum S, Medzhitov R. Toll-like receptors and cancer. Nat Rev Cancer. 2009; 9:57-63.

4. Yu L, Chen S. Toll-like receptors expressed in tumor cells: targets for therapy. Cancer Immunol Immunother. 2008; 57:1271-1278.

5. Medzhitov R, Preston-Hurlburt P, Janeway CA Jr. A human homologue of the Drosophila Toll protein signals activation of adaptive immunity. Nature. 1997; 388:394-397.

6. Kulbe H, Thompson R, Wilson JL, Robinson S, Hagemann T, Fatah R, Gould D, Ayhan A, Balkwill F. The inflammatory cytokine tumor necrosis factor-alpha generates an autocrine tumor-promoting network in epithelial ovarian cancer cells. Cancer Res. 2007; 67:585-592.

7. Sharpless NE, Depinho RA. The mighty mouse: genetically engineered mouse models in cancer drug development. Nat Rev Drug Discov. 2006; 5:741-754.

8. Haricharan S, Brown P. TLR4 has a TP53-dependent dual role in regulating breast cancer cell growth. Proc Natl Acad Sci USA. 2015; 112:E3216-3225.
9. Kim KH, Jo MS, Suh DS, Yoon MS, Shin DH, Lee JH, Choi KU. Expression and significance of the TLR4/MyD88 signaling pathway in ovarian epithelial cancers. World J Surg Oncol. 2012; 10:193.

10. He W, Liu Q, Wang L, Chen W, Li N, Cao X. TLR4 signaling promotes immune escape of human lung cancer cells by inducing immunosuppressive cytokines and apoptosis resistance. Mol Immunol. 2007; 44:2850-2859.

11. Ashkar S, Weber GF, Panoutsakopoulou V, Sanchirico ME, Jansson M, Zawaideh S, Rittling SR, Denhardt DT, Glimcher MJ, Cantor H. Eta-1 (osteopontin): an early component of type-1 (cell-mediated) immunity. Science. $2000 ; 287: 860-864$.

12. Cao W, Liu YJ. Opn: key regulator of $\mathrm{pDC}$ interferon production. Nat Immunol. 2006; 7:441-443.

13. Rangaswami H, Bulbule A, Kundu GC. Osteopontin: role in cell signaling and cancer progression. Trends Cell Biol. 2006; 16:79-87.

14. Rodrigues LR, Teixeira JA, Schmitt FL, Paulsson M, Lindmark-Mansson $\mathrm{H}$. The role of osteopontin in tumor progression and metastasis in breast cancer. Cancer Epidemiol Biomarkers Prev. 2007; 16:1087-1097.

15. Davidson B, Holth A, Moripen L, Trope CG, Shih Ie M. Osteopontin expression in ovarian carcinoma effusions is related to improved clinical outcome. Hum Pathol. 2011; 42:991-997.

16. Thoms JW, Dal Pra A, Anborgh PH, Christensen E, Fleshner N, Menard C, Chadwick K, Milosevic M, Catton C, Pintilie M, Chambers AF, Bristow RG. Plasma osteopontin as a biomarker of prostate cancer aggression: relationship to risk category and treatment response. Br J Cancer. 2012; 107:840-846.

17. Tilli TM, Bellahcene A, Castronovo V, Gimba ER. Changes in the transcriptional profile in response to overexpression of the osteopontin-c splice isoform in ovarian (OvCar-3) and prostate (PC-3) cancer cell lines. BMC Cancer. 2014; 14:433.

18. Zhang J, Yamada O, Kida S, Matsushita Y, Murase S, Hattori T, Kubohara Y, Kikuchi H, Oshima Y. Identification of brefelamide as a novel inhibitor of osteopontin that suppresses invasion of A549 lung cancer cells. Oncol Rep. 2016; 36:2357-2364.

19. Qin L. Osteopontin is a promoter for hepatocellular carcinoma metastasis: a summary of 10 years of studies. Front Med. 2014; 8:24-32. 
20. Rudland PS, Platt-Higgins A, El-Tanani M, De Silva Rudland S, Barraclough R, Winstanley JH, Howitt R, West CR. Prognostic significance of the metastasis-associated protein osteopontin in human breast cancer. Cancer Res. 2002; 62:3417-3427.

21. Hirama M, Takahashi F, Takahashi K, Akutagawa S, Shimizu K, Soma S, Shimanuki Y, Nishio K, Fukuchi Y. Osteopontin overproduced by tumor cells acts as a potent angiogenic factor contributing to tumor growth. Cancer Lett. 2003; 198:107-117.

22. Zhao W, Wang L, Zhang L, Yuan C, Kuo PC, Gao C. Differential expression of intracellular and secreted osteopontin isoforms by murine macrophages in response to toll-like receptor agonists. J Biol Chem. 2010; 285:20452-20461.

23. Shinohara ML, Lu L, Bu J, Werneck MB, Kobayashi KS, Glimcher LH, Cantor H. Osteopontin expression is essential for interferon-alpha production by plasmacytoid dendritic cells. Nat Immunol. 2006; 7:498-506.

24. Inoue M, Moriwaki Y, Arikawa T, Chen YH, Oh YJ, Oliver T, Shinohara ML. Cutting edge: critical role of intracellular osteopontin in antifungal innate immune responses. J Immunol. 2011; 186:19-23.

25. Wang B, Liu SZ, Zheng RS, Zhang F, Chen WQ, Sun XB. Time trends of ovarian cancer incidence in China. Asian Pac J Cancer Prev. 2014; 15:191-193.

26. Gimba ER, Tilli TM. Human osteopontin splicing isoforms: Known roles, potential clinical applications and activated signaling pathways. Cancer Lett. 2013; 331:11-17.

27. Kelly MG, Alvero AB, Chen R, Silasi DA, Abrahams VM, Chan S, Visintin I, Rutherford T, Mor G. TLR-4 signaling promotes tumor growth and paclitaxel chemoresistance in ovarian cancer. Cancer Res. 2006; 66:3859-3868.

28. Luo XZ, He QZ, Wang K. Expression of Toll-like receptor 4 in ovarian serous adenocarcinoma and correlation with clinical stage and pathological grade. Int J Clin Exp Med. 2015; 8:14323-14327.

29. Li Z, Block MS, Vierkant RA, Fogarty ZC, Winham SJ, Visscher DW, Kalli KR, Wang C, Goode EL. The inflammatory microenvironment in epithelial ovarian cancer: a role for TLR4 and MyD88 and related proteins. Tumour Biol. 2016; 37:13279-13286.

30. Sun NK, Huang SL, Chang TC, Chao CC. TLR4 and NFאB signaling is critical for taxol resistance in ovarian carcinoma cells. J Cell Physiol. 2017. [Epub ahead of print]

31. Song G, Ouyang G, Mao Y, Ming Y, Bao S, Hu T. Osteopontin promotes gastric cancer metastasis by augmenting cell survival and invasion through Aktmediated HIF-1alpha up-regulation and MMP9 activation. J Cell Mol Med. 2009; 13:1706-1718.

32. Xu YY, Zhang YY, Lu WF, Mi YJ, Chen YQ. Prognostic value of osteopontin expression in breast cancer: A metaanalysis. Mol Clin Oncol. 2015; 3:357-362.

33. Wang YD, Chen H, Liu HQ, Hao M. Correlation between ovarian neoplasm and serum levels of osteopontin: a metaanalysis. Tumour Biol. 2014; 35:11799-11808.
34. Cabiati M, Gaggini M, Cesare MM, Caselli C, De Simone P, Filipponi F, Basta G, Gastaldelli A, Del Ry S. Osteopontin in hepatocellular carcinoma: A possible biomarker for diagnosis and follow-up. Cytokine. 2017; 99:59-65.

35. Ahmed M, Behera R, Chakraborty G, Jain S, Kumar V, Sharma P, Bulbule A, Kale S, Kumar S, Mishra R, Raja R, Saraswati S, Kaur R, et al. Osteopontin: a potentially important therapeutic target in cancer. Expert Opin Ther Targets. 2011; 15:1113-1126.

36. Moszynski R, Szubert S, Szpurek D, Michalak S, Sajdak $\mathrm{S}$. Role of osteopontin in differential diagnosis of ovarian tumors. J Obstet Gynaecol Res. 2013; 39:1518-1525.

37. Kang CG, Han HJ, Lee HJ, Kim SH, Lee EO. Rhoassociated kinase signaling is required for osteopontininduced cell invasion through inactivating cofilin in human non-small cell lung cancer cell lines. Bioorg Med Chem Lett. 2015; 25:1956-1960.

38. Song J, Ge Z, Yang X, Luo Q, Wang C, You H, Ge T, Deng Y, Lin H, Cui Y, Chu W, Yao M, Zhang Z, et al. Hepatic stellate cells activated by acidic tumor microenvironment promote the metastasis of hepatocellular carcinoma via osteopontin. Cancer Lett. 2015; 356:713-720.

39. Shevde LA, Das S, Clark DW, Samant RS. Osteopontin: an effector and an effect of tumor metastasis. Curr Mol Med. $2010 ; 10: 71-81$.

40. Mantovani A. Cancer: Inflaming metastasis. Nature. 2009; 457:36-37.

41. Hanahan D, Weinberg RA. Hallmarks of cancer: the next generation. Cell. 2011; 144:646-674.

42. Oishi Y, Spann NJ, Link VM, Muse ED, Strid T, Edillor C, Kolar MJ, Matsuzaka T, Hayakawa S, Tao J, Kaikkonen MU, Carlin AF, Lam MT, et al. SREBP1 contributes to resolution of pro-inflammatory TLR4 signaling by reprogramming fatty acid metabolism. Cell Metab. 2017; 25:412-427.

43. Kidd LC, Rogers EN, Yeyeodu ST, Jones DZ, Kimbro KS. Contribution of toll-like receptor signaling pathways to breast tumorigenesis and treatment. Breast Cancer. 2013; 5:43-51.

44. Castellano G, Malaponte G, Mazzarino MC, Figini M, Marchese F, Gangemi P, Travali S, Stivala F, Canevari $\mathrm{S}$, Libra M. Activation of the osteopontin/matrix metalloproteinase-9 pathway correlates with prostate cancer progression. Clin Cancer Res. 2008; 14:7470-7480.

45. Chen YJ, Wei YY, Chen HT, Fong YC, Hsu CJ, Tsai CH, Hsu HC, Liu SH, Tang CH. Osteopontin increases migration and MMP-9 up-regulation via alphavbeta3 integrin, FAK, ERK, and NF-kappaB-dependent pathway in human chondrosarcoma cells. J Cell Physiol. 2009; 221:98-108.

46. Tilli TM, Franco VF, Robbs BK, Wanderley JL, da Silva FR, de Mello KD, Viola JP, Weber GF, Gimba ER. Osteopontin-c splicing isoform contributes to ovarian cancer progression. Mol Cancer Res. 2011; 9:280-293.

47. Liu J, Liu Q, Wan Y, Zhao Z, Yu H, Luo H, Tang Z. Osteopontin promotes the progression of gastric cancer through the NF- $\kappa$ B pathway regulated by the MAPK and PI3K. Int J Oncol. 2014; 45:282-290. 